\title{
Evolving Targets For Heart Failure: The Journey So Far
}

\section{Giuseppe MC Rosano}

1. Centre for Clinical \& Basic Research IRCCS San Raffaele Pisana, via della Pisana, 235, 00163 Rome, Italy

Corresponding author:

Centre for Clinical \& Basic Research IRCCS

San Raffaele Pisana,

via della Pisana, 235, 00163 Rome, Italy

Email: giuseppe.rosano@gmail.com

\begin{abstract}
The treatment of heart failure has included vasodilators, positive inotropes and most successfully neuro-hormonal blockade. Recent research has looked at metabolic and immune modulatory approaches, and implantable, mainly electrical devices. The near future in pharmacological research for heart failure remains focussed on classic methodologies and small molecules, but despite significant improvements we still know relatively little of the complex interactions in HF particularly for HFpEF. Pharmacotherapy will in future be combined with advances in biotechnology, nanotechnology and devices and a digital revolution will help us to monitor patients at a distance, using wireless devices. Heart failure research has achieved much over the last 4 decades but the pace of innovation and research has not abated and future advances in this disabling condition are indeed likely.
\end{abstract}

Keywords: Heart Failure; Therapeutics; Randomised controlled trials

Citation: Rosano GMC. Evolving targets for heart failure: the journey so far. International Cardiovascular Forum Journal. 2019;17:2-5. DOI: 10.17987/icfj.v17i0.589

\section{Introduction}

Until the 1970s the only treatments for the management of heart failure were based on bed rest, restriction of physical activity, fluid restriction and pharmacological therapy limited to diuretics and digitalis. At the time research efforts in developing new heart failure treatments mostly focused on the kidney rather than the heart as a target. Since then the evolution of the treatment of heart failure has been prolific, starting with the development of vasodilators, positive inotropes and more recently moving to neuro-hormonal blockade, metabolic and immune modulatory approaches, and implantable, mainly electrical devices.

\section{Haemodynamics and Inotropy}

From the mid-1970s, vasodilators had been studied with the aim of reducing afterload and to increase cardiac efficiency and cardiac output.[1] It was thought that the effect of vasodilators on left ventricular ejection fraction, ventricular diastolic pressure and cardiac energetics would be advantageous for patients with heart failure. However, the Vasodilator-Heart Failure Trial (V- HeFT I) showed that, despite short-term haemodynamic improvement, afterload reduction did not improve survival.[2] It soon become evident that the haemodynamic effects of vasodilators were not the main driver of longer-term benefits, and subsequently a series of trials showed that patients treated with pure vasodilators were at greater risk of developing worsening HF and mortality.[3-6]

The description by Sarnoff of ventricular function curves brought the idea of developing drugs aimed at improving ventricular contractility.[7] Therefore, the possibility of shifting from one Starling curve to another by improving the 'contractile' state of the heart became a major target. Overcoming the difficulties in measuring contractility, it become evident that improving the impaired contractility of the left ventricle in patients with chronic HF would be a meaningful target. Therefore, research focused on understanding the causes of the impaired myocardial contractility. The recognition of a central role of abnormal calcium movements and energy starvation stimulated the development of novel inotropic drugs. These drugs were developed on the assumption that since left ventricular ejection fraction (LVEF) correlates with survival, increasing LVEF should improve prognosis. Despite a sound rationale it become evident that despite an improvement in cardiac performance, the early positive inotropic agents had a detrimental effect on survival. A few years later the picture was completed by the evidence that also cardiac glycosides, the earliest inotropic agents, that had long been the mainstay of heart failure therapy, were not effective at improving survival in patients with heart failure in sinus rhythm.[8]

\section{The neuroendocrine years}

Starling's law of the heart and the neuroendocrine response were considered as compensatory mechanisms. In the 1980s Peter Harris of the National Heart and Lung Institute in London, and his group hypothesised that the neuroendocrine activation observed in patients with heart failure was a maladaptive response and not 
part of a maintained compensatory mechanism.[9-13] This novel interpretation of neuro-endocrine activation led to a new way of treating heart failure, and became considered a defining hallmark of the heart failure syndrome, persistent neuroendocrine activation. As a consequence, this new approach led to the evaluation and later introduction of angiotensin converting enzyme inhibitors (ACEls), beta-blockers (BBs) and mineralocorticoid receptor antagonists (MRAs) as treatments for HF. ACEls were the first class of drug to show a significant and sizeable reduction in the risk of death and hospitalisation in patients with heart failure with reduced ejection fraction (HFrEF), regardless of its severity. [14] Beta-blockers were introduced with more caution given the negative inotropic effect of first and second generation betablockers. They were, indeed paradoxically found to improve left ventricular ejection fraction, improve symptoms and decrease mortality and hospitalisation when administered chronically, provided of course the patient can be supported during a slow period of introduction and up-titration.[15] Both classes of drugs, ACEis and BBs were demonstrated to reduce left ventricular remodelling and to be beneficial regardless of the aetiology of heart failure, age, race or gender.[16]

Later, the MRAs were shown to have a beneficial prognostic effect on top of therapy with ACEls and BBs. The picture was completed with the development of newer angiotensin receptor blockers (ARBs). At this stage of neuro-endocrine focused research, atrial natriuretic peptide (ANP) was thought to be beneficial in heart failure because of its vasodilatory capacity. [17] However, this peptide had not been shown in human studies to positively modify cardiac structure, function or improve survival.[18-19]

The neuroendocrine story stimulated radical changes in the management of heart failure, from vasodilators to anti-renin angiotensin-aldosterone (RAASI) drugs, from positive inotropes to drugs with a short-term negative inotropic effect, such as BBs, that progressed to effectively become positive inotropes in heart failure over the medium to longer term due to their ability to induce left ventricular reverse remodelling and an increase in left ventricular function without increasing oxygen consumption.

The effect of beta-blockers in heart failure highlighted the paradox of the altered relationship between heart rate and contraction. In normal physiological states, the contractile force of a healthy papillary muscle increases proportionately to the increase in its rate of contraction. In contrast, in HF this relationship becomes inverse, and the contraction strength decreases in response to increased heart frequency. As a result, in HF, increasing heart rate is associated with a reduction of left ventricular ejection fraction.[20] This evidence led to the introduction of a newer class of drugs that selectively reduce heart rate and increase ejection fraction, whilst be devoid of any direct effect on cardiac myocytes or peripheral vascular resistance. Ivabradine (see chapter 7 ), a specific inhibitor of the If current in the sinoatrial node, that induces a selective heart rate reduction, was found to have a positive effect on remodelling and ejection fraction.[21-23]

\section{The Millennium}

In the new millennium heart failure research turned to a combination of devices (which are beyond the scope of this chapter), molecular biology, genetics and stem cells. Despite huge excitement at their potential, the heralded benefit of these therapies has not yet been achieved clinically. Despite the demonstration of the molecular cause of a form of familial hypertrophic cardiomyopathy, a mis-sense mutation in the cardiac beta-myosin heavy chain gene, being reported in the early 90 s, the replacement of faulty genes with correct copies delivered by viral vectors has not been proven to be effective to date. A newly discovered type of regulation termed epigenetics has been more recently identified as a possible therapeutic target for heart failure therapies.[24] Linked to epigenetics is the concept of micro RNAs (miRNAs). These are small non-coding RNA segments that regulate gene transcription and protein formation by silencing selected messenger RNA strands. Preclinical research into miRNAs suggests the importance of these molecules for many cardiac myocyte functions in the failing heart, from calcium cycling to ventricular hypertrophy.[25]

The enthusiasm for stem cell therapy led to the belief that stem cell implantation could re-generate the myocardium and improve cardiac function. Autologous bone marrow-derived mono nuclear cells were considered first for therapeutic purposes. However, the results of their use have never been compelling and this approach has been not found effective for clinical use. [26-28] Subsequently, mesenchymal stem cells harvested from the adipose tissue were also considered, but they also have been found not to have a significant therapeutic effect in patients with heart failure.[29] Hope now has focused on the therapeutic use of autologous stem cells. The efficacy of this technology remains under investigation.[26] However, the challenges of finding the optimal cell type, quantity, processing method, administration route, and establishing efficacy and safety remain unsolved.

\section{The future}

The near future in pharmacological research for heart failure remains focussed on classic methodologies and small molecules. The results in HFrEF from the PARADIGM-HF study, in which a smart fixed dose combination of sacubitril and valsartan (LCZ696) significantly improved prognosis compared with treatment with the ACEi enalapril suggests that there is still room for further developments using this approach, even though other attempts at comprehensive neurohormonal modulation have failed, such as when vaospressin and/or endothelin antagonists were added to the triad of ACEls, BBs and MRAs.

\section{Areas of relative failure}

The past decades have led to a significant improvement in our understanding and treatment of chronic HFrEF, whereas in stark contrast, no effective therapies have been developed for acute heart failure (AHF) or for heart failure with preserved ejection fraction (HFpEF).[30] These two conditions however, are a mixed bag of different aetiologies that may well need differing and more differentiated therapeutic approaches. The identification of different phenotypes helping identify the multifaceted pathophysiology of these two conditions may be an essential precursor to the development of effective therapies.

We still lack the unifying hypotheses for both AHF and HFpEF that would allow more soundly based therapeutic approaches to be developed. We also lack for both conditions adequate surrogate end points that may shed the light on the efficacy of newer therapies at an earlier stage of the development 
pathway. Many promising compounds have failed in largescale randomized clinical trials in acute heart failure, despite the attractive conceptual foundations underpinning their use.[31-34] We are still missing the link between acute symptomatic relief and long-term risk reduction, which has not been achieved with any agent used in AHF to date.

\section{Conclusions}

Despite significant improvements in our understanding of heart failure over 4 decades we still know relatively little of the complex interactions of the disorder. Pharmacotherapy is likely to play an integral role for the foreseeable future. This remains true, despite the fact that we live in a modern, technological world where advances in biotechnology, nanotechnology and devices continue to offer tantalising possibilities of replacing failing cardiomyocytes with gene or stem cell therapy or to correct the dysfunctional cells using chimeric antigen receptors. The digital revolution will help us to monitor patients at a distance, using wireless devices. This may help to identify newer innovative approaches to heart failure management through a combination of health- and bioinformatics, personalised medicine and smart drug design. Heart failure research has achieved much over the last 4 decades but the pace of innovation and research has not abated and future advances in this disabling condition are indeed likely.

\section{Declarations of interest}

The authors declare no conflict of interest.

\section{Acknowledgements}

The authors state that they abide by the authors' responsibilities and ethical publishing guidelines of the International Cardiovascular Forum Journal.[35]

\section{References}

1. Cohn JN, Franciosa JA. Vasodilator therapy of cardiac failure. N Engl J Med 1977;297:27-31.

2. Cohn JN, Archibald DG, Ziesche S, Franciosa JA, Harston WE, Tristani FE, Dunkman WB, Jacobs W, Francis GS, Flohr KH, Goldman S, Cobb FR, Shah PM, Saunders R, Fletcher RD, Loeb HS, Hughes VC, Baker B. Effect of Vasodilator Therapy on Mortality in Chronic Congestive Heart Failure. New England Journal of Medicine 1986;314:1547-1552.

3. Elkayam U, Amin J, Mehra A, Vasquez J, Weber L, Rahimtoola SH. A prospective, randomized, double-blind, crossover study to compare the efficacy and safety of chronic nifedipine therapy with that of isosorbide dinitrate and their combination in the treatment of chronic congestive heart failure. Circulation 1990;82:1954-1961.

4. Franciosa JA, Jordan RA, Wilen MM, Leddy CL. Minoxidil in patients with chronic left heart failure: contrasting hemodynamic and clinical effects in a controlled trial. Circulation 1984;70:63-68.

5. Goldstein RE, Boccuzzi SJ, Cruess D, Nattel S. Diltiazem increases lateonset congestive heart failure in postinfarction patients with early reduction in ejection fraction. The Adverse Experience Committee; and the Multicenter Diltiazem Postinfarction Research Group. Circulation 1991;83:52-60.

6. Francis GS. Pathophysiology of chronic heart failure. Am J Med 2001;110 Suppl 7A:37S-46S.

7. Sarnoff SJ. Myocardial contractility as described by ventricular function curves; observations on Starling's law of the heart. Physiol Rev 1955;35:107-122.

8. Cleland JGF. Beta-blockers for heart failure: why, which, when, and where. Med Clin North Am 2003;87:339-371.

9. Anand IS, Ferrari R, Kalra GS, Wahi PL, Poole-Wilson PA, Harris PC. Edema of cardiac origin. Studies of body water and sodium, renal function, hemodynamic indexes, and plasma hormones in untreated congestive cardiac failure. Circulation 1989;80:299-305.

10. Anand IS, Ferrari R, Kalra GS, Wahi PL, Poole-Wilson PA, Harris PC. Pathogenesis of edema in constrictive pericarditis. Studies of body water and sodium, renal function, hemodynamics, and plasma hormones before and after pericardiectomy. Circulation 1991;83:1880-1887.

11. Anand IS, Chandrashekhar Y, Ferrari R, Sarma R, Guleria R, Jindal SK, Wahi PL, Poole-Wilson PA, Harris P. Pathogenesis of congestive state in chronic obstructive pulmonary disease. Studies of body water and sodium, renal function, hemodynamics, and plasma hormones during edema and after recovery. Circulation 1992;86:12-21.

12. Ferrari R, Panzali AF, Poole-Wilson PA, Anand IS. Plasma CGRP-like immunoreactivity in treated and untreated congestive heart failure. Lancet 1991;338:1084.

13. Cargnoni A, Condorelli E, Boraso A, Comini L, De Giuli F, Pasini E, Ferrari R. Role of timing of administration in the cardioprotective effect of fructose1,6-bisphosphate. Cardiovasc Drugs Ther 1992;6:209-217.

14. Garg R, Yusuf S. Overview of randomized trials of angiotensin- converting enzyme inhibitors on mortality and morbidity in patients with heart failure. Collaborative Group on ACE Inhibitor Trials. Jama 1995;273:1450-1456.

15. Brophy JM, Joseph L, Rouleau JL. Beta-blockers in congestive heart failure. A Bayesian meta-analysis. Ann Intern Med 2001;134:550-560.

16. Damman K, Tang WHW, Felker GM, Lassus J, Zannad F, Krum H, McMurray JJV. Current evidence on treatment of patients with chronic systolic heart failure and renal insufficiency: practical considerations from published data. J Am Coll Cardiol 2014;63:853-871.

17. Anand IS, Kalra GS, Ferrari R, Harris P, Poole-Wilson PA. Hemodynamic, hormonal, and renal effects of atrial natriuretic peptide in untreated congestive cardiac failure. Am Heart J 1989;118:500-505

18. Gottlieb SS, Kukin ML, Ahern D, Packer M. Prognostic importance of atrial natriuretic peptide in patients with chronic heart failure. J Am Coll Cardiol 1989;13:1534-1539.

19. Hata N, Seino Y, Tsutamoto T, Hiramitsu S, Kaneko N, Yoshikawa T, Yokoyama H, Tanaka K, Mizuno K, Nejima J, Kinoshita M. Effects of carperitide on the long-term prognosis of patients with acute decompensated chronic heart failure: the PROTECT multicenter randomized controlled study. Circ J 2008;72:1787-1793.

20. Ferrari R. Ivabradine: heart rate and left ventricular function. Cardiology 2014;128:226-230.

21. Fox K, Ford I, Steg PG, Tendera M, Ferrari R. BEAUTIFUL Investigators. Ivabradine for patients with stable coronary artery disease and leftventricular systolic dysfunction (BEAUTIFUL): a randomised, double-blind, placebo-controlled trial. Lancet 2008;372:807-816.

22. Swedberg K, Komajda M, Böhm M, Borer JS, Ford I, Dubost-Brama A, Lerebours G, Tavazzi L, Investigators S, others. Ivabradine and outcomes in chronic heart failure (SHIFT): a randomised placebo-controlled study. The Lancet 2010;376:875-885.

23. Ferrari R, Fox K. Heart rate reduction in coronary artery disease and heart failure. Nat Rev Cardiol 2016;13:493-501.

24. Goldberg $A D$, Allis $C D$, Bernstein E. Epigenetics: a landscape takes shape. Cell 2007;128:635-638.

25. Kumarswamy R, Thum T. Non-coding RNAs in cardiac remodeling and heart failure. Circ Res 2013;113:676-689

26. Jeevanantham V, Butler M, Saad A, Abdel-Latif A, Zuba-Surma EK, Dawn B. Adult bone marrow cell therapy improves survival and induces longterm improvement in cardiac parameters: a systematic review and metaanalysis. Circulation 2012;126:551-568.

27. Pfister O, Della Verde G, Liao R, Kuster GM. Regenerative therapy for cardiovascular disease. Transl Res 2014;163:307-320.

28. Valgimigli M, Rigolin GM, Cittanti C, Malagutti P, Curello S, Percoco G, Bugli AM, Della Porta M, Bragotti LZ, Ansani L, Mauro E, Lanfranchi A, Giganti M, Feggi L, Castoldi G, Ferrari R. Use of granulocyte-colony stimulating factor during acute myocardial infarction to enhance bone marrow stem cell mobilization in humans: clinical and angiographic safety profile. Eur Heart J 2005;26:1838-1845.

29. Fortini C, Cesselli D, Beltrami AP, Bergamin N, Caragnano A, Moretti L, Cecaro F, Aquila G, Rizzo P, Riberti C, Tavazzi L, Fucili A, Beltrami CA, Ferrari R. Alteration of Notch signaling and functionality of adipose tissue derived mesenchymal stem cells in heart failure. Int J Cardiol 2014;174:119-126.

30. Ponikowski P, Voors AA, Anker SD, Bueno H, Cleland JGF, Coats AJS, FalkV,Gonzalez-JuanateyJR,HarjolaV-P,JankowskaEA,JessupM, Linde C, Nihoyannopoulos P, Parissis JT, Pieske B, Riley JP, Rosano GMC, Ruilope LM, Ruschitzka F, Rutten FH, van der MP. Authors/Task Force Members 2016 ESC Guidelines for the diagnosis and treatment of acute and chronic heart failure: The Task Force for the diagnosis and treatment of acute and chronic heart failure of the European Society of Cardiology (ESC). Developed with the special contribution of the Heart Failure Association (HFA) of the ESC. Eur Heart J 2016;37:2129-2200.

31. Mebazaa A, Nieminen MS, Packer M, Cohen-Solal A, Kleber FX, Pocock SJ, Thakkar R, Padley RJ, Poder P, Kivikko M. SURVIVE Investigators. Levosimendan vs dobutamine for patients with acute decompensated heart failure: the SURVIVE Randomized Trial. JAMA 2007;297:1883-1891.

32. Packer M, Carver JR, Rodeheffer RJ, Ivanhoe RJ, DiBianco R, Zeldis SM, Hendrix GH, Bommer WJ, Elkayam U, Kukin ML. Effect of oral milrinone on mortality in severe chronic heart failure. The PROMISE Study Research Group. N Engl J Med 1991;325:1468-1475.

33. McMurray JJV, Teerlink JR, Cotter G, Bourge RC, Cleland JGF, Jondeau G, Krum H, Metra M, O'connor CM, Parker JD, Torre-Amione G, Veldhuisen DJ. V, Lewsey J, Frey A, Rainisio M, Kobrin I. VERITAS Investigators. Effects of tezosentan on symptoms and clinical outcomes in patients with acute heart failure: the VERITAS randomized controlled trials. JAMA 2007;298:2009-2019. 
34. Cannon JA, McKean AR, Jhund PS, McMurray JJV. What can we learn from RELAX-AHF compared to previous AHF trials and what does the future hold? Open Heart 2015;2:e000283.

35. Shewan LG, Coats AJS, Henein MY. Authors' Responsibilities and Ethical Publishing. International Cardiovascular Forum Journal 2018;13:3-4, DOI: 10.17987/icfj.v13i0.525 